Discussion Paper No. 1017

\title{
COUNTRY SIZE, SPECIALIZATION PATTERNS AND SECULAR DEMAND STAGNATION*
}

Yoshiyasu Ono

November 2017

The Institute of Social and Economic Research Osaka University

6-1 Mihogaoka, Ibaraki, Osaka 567-0047, Japan 


\title{
Country size, specialization patterns and secular demand stagnation*
}

\author{
by \\ Yoshiyasu Ono ${ }^{\dagger}$
}

\begin{abstract}
Using a dynamic two-country two-commodity Ricardian model where preference for money (or wealth) leads to aggregate demand deficiency, this paper examines the relationship between the two countries' relative population size and their specialization patterns, employment and consumption. When the countries have similar population sizes, they specialize in respective commodities with comparative advantage. In this case a larger foreign, or a smaller home, population raises the relative price of the home commodity. It raises home real income and consumption per capita if full employment prevails in the home country. If unemployment appears, however, home employment and consumption per capita decrease.
\end{abstract}

JEL classification: F41, E24, E32

Keywords: secular demand stagnation, liquidity trap, unemployment, population, specialization pattern.

* The author thanks seminar participants at Osaka and Kobe Universities for their valuable comments. A part of this research was carried out while the author visited CES, Munich University. Financial supports by JSPS KAKENHI Grant (JP15H05728 and JP22530178) and the Joint Usage/Research Center Program by the Ministry of Education, Culture, Sports, Science and Technology, Japan, are gratefully acknowledged.

† Institute of Social and Economic Research, Osaka University, 6-1, Mihogaoka, Ibaraki, Osaka 567-0047, JAPAN. E-mail: ono@iser.osaka-u.ac.jp. 


\section{Introduction}

This paper considers a dynamic two-country two-commodity Ricardian model with endogenous specialization patterns where secular aggregate demand stagnation can occur in one or both countries. Using this model, it analyzes the relationship between the two countries' relative population size and their specialization patterns, employment and consumption.

Nowadays persistent stagnation of aggregate demand and depopulation may be the two major threats that many developed countries face. They welcome expansions of foreign demand in hope of creating new home employment but worry about home depopulation in fear of decreasing production capacity. This is indeed the case for Japan. Japan regards depopulation as a threat of being dominated by Asian emerging economies but favorably views the emergence because it is expected to expand foreign demand for Japanese products and stimulate the Japanese economy. This paper shows that a change in the international relative population size yields quite different effects on income and consumption per capita, depending on whether full employment prevails or not.

In a Ricardian trade model with two commodities, if the home population is much larger than the foreign one, the home country produces both commodities while the foreign country specializes in the commodity with comparative advantage. ${ }^{1}$ In this case, the international relative price of the two commodities equals the home autarky one, which is not affected by a change in the relative population. Thus, population changes vary neither per-capita income nor consumption in the two countries. If the two countries have similar population sizes, they specialize in respective commodities with comparative advantage. In this case, as the relative foreign population is larger, the relative price approaches the foreign autarky level from the

\footnotetext{
${ }^{1}$ Ono and Shibata (2006) shows that this Ricardian property holds also in a dynamic Heckscher-Ohlin model with endogenous capital accumulation.
} 
home autarky level, improving the home terms of trade. It expands home, and reduces foreign, per-capita income and consumption as long as full employment prevails in both countries.

If households have insatiable preference for money (or wealth) holding, however, there is an upper bound of consumption, as proved by Ono $(1994,2001)$ and Ono and Ishida (2014). In this case, an improvement in the terms of trade may increase the real value of full-employment production so much as to exceed the upper bound of home consumption and yield aggregate demand deficiency. Then, a further rise in the relative price of the home commodity, due to an increase in the relative foreign population, decreases world demand for the home commodity, reduces home employment and consumption per capita, and worsens aggregate demand stagnation.

The crux of the present analysis is aggregate demand stagnation due to preference for money (or wealth). Analyses on stagnation have recently extended in many ways. Some economists attribute it to productivity declines and others to market distortions, but there are not many that consider aggregate demand shortages. Typical productivity approaches are Kehoe and Prescott (2002), Hayashi and Prescott (2002) and McGratten and Prescott (2012). DSGE models take business fluctuations to be generated by monopolistic competition with the Calvo pricing (1983) in the commodity or labor market, where no aggregate demand shortages appear. They are Yun (1996), Erceg et al. (2000), Smets and Wouters (2003, 2005, 2007) and Christiano et al. (2005) in the case of a closed economy and Adolfson et al. $(2007,2008)$ in the case of an open economy. Kiyotaki and Moore (1997), Aghion et al. (1999), Matsuyama (2007), Hall (2011), Liu and Wang (2014) and Azariadis and Kaas (2016) consider a credit constraint that firms or investors face, and mention that the constraint distorts capital allocation and deteriorates productivity. A mechanism of unemployment that persists in a steady state is presented by the search theory (e.g. Pissarides, 2000) but it is of the frictional type. 
While those researches do not treat aggregate demand shortages, Krugman (1998) proposes a period model in which aggregate demand shortages appear due to a zero lower bound of the nominal interest rate and nominal price rigidities. ${ }^{2}$ In this setting aggregate demand shortages appear only in the period in which an unexpected shock arises, and disappear in the long run.

However, the present stagnation of Japan lasts for more than two decades. It may not be plausible to consider that negative productivity shocks last more than two decades in Japan or that Japan’s market adjustment process takes such a long time. Similar consideration may apply to the other developed countries that have been suffering from aggregate demand stagnation since the financial crisis of 2008, such as EU and the USA.

This paper adopts yet another approach to stagnation. It considers secular stagnation of aggregate demand due to preference of money (or wealth) holding, which arises in rich countries even without market distortions. This property was firstly presented by Ono (1994, 2001) and has recently rediscovered by Michaillat and Saez (2014) and Michau (2015). Moreover, Ono (2006, 2014, 2017) has extended the model to an open-economy context where specialization patterns are exogenously given. He has analyzed own and international spillover effects of productivity improvements, fiscal expansions and trade policies on employment, income and consumption. This paper introduces endogenous specialization patterns to that framework and examines the relationship between the relative population size and the two countries’ specialization patterns, employment and consumption.

\footnotetext{
${ }^{2}$ Eggertsson and Krugman (2012) consider a period model where some firms' price settings are sluggish and there are borrowers who face credit constraints and savers who do not. A credit crunch makes borrowers reduce consumption and leads to aggregate demand deficiency.
} 


\section{Household and Firm Behavior}

Suppose that there are two countries, home and foreign, and two commodities, 1 and 2. Their populations are respectively $L$ and $L^{*}$. Variables with asterisk * imply foreign ones.

Households: Households in the two countries have the same utility functional:

$$
\int_{0}^{\infty}\left[\hat{u}\left(c_{1}^{(*)}, c_{2}^{(*)}\right)+v\left(m^{(*)}\right)\right] \exp (-\rho t) d t,
$$

where $c_{i}^{(*)}$ and $m^{(*)}$ are respectively each household's consumption of commodity $i$ ( $i=$ $1,2)$ and real money holding.

Function $\hat{u}(.,$.$) is homothetic and hence, once real aggregate consumption c^{(*)}$ is given at each point in time, the optimal levels of $c_{1}^{(*)}$ and $c_{2}^{(*)}$ satisfy

$$
\begin{gathered}
\hat{u}_{2}\left(c_{1}^{(*)}, c_{2}^{(*)}\right) / \hat{u}_{1}\left(c_{1}^{(*)}, c_{2}^{(*)}\right)=p_{2}(\omega) / p_{1}(\omega)=\omega, \\
p_{1}(\omega) c_{1}^{(*)}=\delta(\omega) c^{(*)}, \quad p_{2}(\omega) c_{1}^{(*)}=[1-\delta(\omega)] c^{(*)}, \\
1>\delta(\omega)>0, \quad \delta^{\prime}(\omega)>0,
\end{gathered}
$$

where $\omega$ is the relative price of commodity 2 to commodity $1, p_{i}(\omega)$ is the real price of commodity $i(i=1,2)$, and $\delta(\omega)$ is the share of consumption expenditure on commodity 1 . The real and nominal prices satisfy

$$
p_{1}(\omega)=\frac{P_{1}}{P}=\frac{P_{1}^{*}}{P^{*}}, \quad p_{2}(\omega)=\frac{P_{2}}{P}=\frac{P_{2}^{*}}{P^{*}}, \quad \epsilon=\frac{P_{1}}{P_{1}^{*}}=\frac{P_{2}}{P_{2}^{*}},
$$

where $P^{(*)}$ is the general price index, $P_{i}^{(*)}$ is the nominal price of commodity $i$ measured in each currency, and $\epsilon$ is the nominal exchange rate. The general price index is chosen so that a change in the relative price $\omega$ will not affect the level of $\hat{u}(.,$.$) . Therefore, \hat{u}(.,$.$) into which$ $c_{1}^{(*)}$ and $c_{2}^{(*)}$ given in (2) are substituted satisfies

$$
\hat{u}\left(\frac{\delta(\omega)}{p_{1}(\omega)} c^{(*)}, \frac{1-\delta(\omega)}{p_{2}(\omega)} c^{(*)}\right)=\phi\left(c^{(*)}\right) \hat{u}\left(\frac{\delta(\omega)}{p_{1}(\omega)}, \frac{1-\delta(\omega)}{p_{2}(\omega)}\right) \equiv u\left(c^{(*)}\right),
$$




$$
\frac{d \widehat{u}\left(\frac{\delta(\omega)}{p_{1}(\omega)^{\prime}}, \frac{1-\delta(\omega)}{p_{2}(\omega)}\right)}{d \omega}=\hat{u}_{1} \frac{d\left(\frac{\delta(\omega)}{p_{1}(\omega)}\right)}{d \omega}+\hat{u}_{2} \frac{d\left(\frac{1-\delta(\omega)}{p_{2}(\omega)}\right)}{d \omega}=0 .
$$

Because $\hat{u}_{2} / \hat{u}_{1}=\omega=p_{2}(\omega) / p_{1}(\omega)$ from (2), the second equation in (4) yields

$$
p_{1}^{\prime}(\omega)=-\frac{(1-\delta) p_{1}}{\omega}<0, \quad p_{2}^{\prime}(\omega)=\frac{\delta p_{2}}{\omega}=\delta p_{1}>0
$$

From (3) one obtains

$$
P=\epsilon P^{*},
$$

of which the time derivative yields

$$
\pi=\frac{\dot{\epsilon}}{\epsilon}+\pi^{*}
$$

where $\pi$ and $\pi^{*}$ are respectively the home and foreign inflation rates. From this equation and the non-arbitrage condition between home and foreign assets:

$$
R=\frac{\dot{\epsilon}}{\epsilon}+R^{*}
$$

where $R$ and $R^{*}$ respectively represent the home and foreign nominal interest rates, one finds

$$
R-\pi=r=R^{*}-\pi^{*},
$$

i.e., the real interest rate $r$ is internationally the same.

From the first equation in (4), the utility functional given by (1) reduces to

$$
\begin{aligned}
& \int_{0}^{\infty}\left[u\left(c^{(*)}\right)+v\left(m^{(*)}\right)\right] \exp (-\rho t) d t \\
& u^{\prime}>0, \quad u^{\prime \prime}<0, \quad v^{\prime}>0, \quad v^{\prime \prime}<0,
\end{aligned}
$$

which is maximized subject to each flow budget equation and asset constraint:

$$
\dot{a}^{(*)}=r a^{(*)}+w^{(*)} x^{(*)}-c^{(*)}-R^{(*)} m^{(*)}, \quad a^{(*)}=m^{(*)}+b^{(*)},
$$

where $w^{(*)}$ is real wage, $x^{(*)}$ is realized employment, $a^{(*)}$ is real total asset, $b^{(*)}$ is real international lending and borrowing, and the real interest rate $r$ is internationally the same, as shown in (6). Because all firms are assumed to be competitive and utilize only labor as input with constant-returns-to-scale technology, the firm values are zero. Therefore, $a^{(*)}$ consists of 
money $m^{(*)}$ and international net asset $b^{(*)}$. Each household's labor endowment is normalized to 1 and may be underemployed -i.e., $x^{(*)}$ can be regarded as the employment rate.

From the Hamiltonian function of the utility maximization:

$$
H^{(*)}=u\left(c^{(*)}\right)+v\left(m^{(*)}\right)+\lambda^{(*)}\left(r a^{(*)}+w^{(*)} x^{(*)}-c^{(*)}-R^{(*)} m^{(*)}\right),
$$

one obtains the first-order optimal conditions: ${ }^{3}$

$$
\lambda^{(*)}=u^{\prime}\left(c^{(*)}\right), \quad \lambda^{(*)} R^{(*)}=v^{\prime}\left(m^{(*)}\right), \quad \frac{\dot{\lambda}^{(*)}}{\lambda^{(*)}}=\rho-r .
$$

Equations (6) and (8) yield

$$
\eta^{*} \frac{\dot{c}^{*}}{c^{*}}=\eta \frac{\dot{c}}{c}=r-\rho, \quad R^{(*)}\left(=r+\pi^{(*)}\right)=\frac{v^{\prime}\left(m^{(*)}\right)}{u^{\prime}\left(c^{(*)}\right)}
$$

where $\eta^{(*)}=-u^{\prime \prime}\left(c^{(*)}\right) c^{(*)} / u^{\prime}\left(c^{(*)}\right)$.

Firms: The home and foreign labor productivities of commodity $i(i=1,2)$ are respectively $\theta_{i}$ and $\theta_{i}^{*}$, both of which are constant. Without loss of generality, they satisfy

$$
\frac{\theta_{1}}{\theta_{2}}>\frac{\theta_{1}^{*}}{\theta_{2}^{*}}
$$

i.e., the home (or foreign) country has comparative advantage in production of commodity 1 (or commodity 2). Because all firms are competitive, if sector $i(i=1,2)$ operates,

$$
p_{i}(\omega) \theta_{i}=w, \quad p_{i}(\omega) \theta_{i}^{*}=w^{*}
$$

\section{Three specialization patterns}

Because the labor productivities of the two commodities are constant, at least one of the two countries specializes in the sector with the comparative advantage represented by (12). The home (or foreign) country specializes in commodity 1 (or 2 ) if it specializes. This section finds

\footnotetext{
${ }^{3}$ Apparently, by replacing $u(c)$ with $\hat{u}\left(c_{1}, c_{2}\right)$ one obtains the intratemporal and intertemporal optimal conditions given by (2) and (8) all at once.
} 
that three specialization patterns appear depending on the relative population size $\gamma\left(=L^{*} / L\right)$. Apparently, $\gamma$ increases with a larger foreign population and a smaller home population.

From the home and foreign demand functions of the two commodities given in (2), world demand for commodity 1 and that for commodity 2 are respectively $\delta(\omega)\left(L c+L^{*} c^{*}\right) / p_{1}(\omega)$ and $[1-\delta(\omega)]\left(L c+L^{*} c^{*}\right) / p_{2}(\omega)$. Therefore, the market clearing of the commodities yields

$$
\begin{gathered}
\frac{\delta(\omega)}{p_{1}(\omega)}\left(c+\gamma c^{*}\right)=\theta_{1} x_{1}+\theta_{1}^{*} \gamma x_{1}^{*}, \quad \gamma=L^{*} / L, \\
\frac{\theta_{2} x_{2}+\theta_{2}^{*} \gamma x_{2}^{*}}{\theta_{1} x_{1}+\theta_{1}^{*} \gamma x_{1}^{*}}=\varphi(\omega) \equiv \frac{1-\delta(\omega)}{\omega \delta(\omega)}, \quad \varphi^{\prime}(\omega)<0,
\end{gathered}
$$

where $\varphi(\omega)$ is the demand ratio of commodity 2 over commodity 1 , and $x_{i}$ and $x_{i}^{*}$ are respectively home and foreign employment per capita in sector $i(i=1,2)$, satisfying

$$
x_{1}+x_{2}=x, \quad x_{1}^{*}+x_{2}^{*}=x^{*} .
$$

Under the comparative advantage assumed in (10) one obtains the following specialization patterns, where the numbers given after h or f imply the commodities produced in the home (h) or foreign (f) country:

$$
\begin{aligned}
& \text { Pattern (h12-f2): } 0<x_{i}<x(\text { for } i=1,2), \quad\left(x_{1}^{*}, x_{2}^{*}\right)=\left(0, x^{*}\right), \\
& \text { Pattern (h1-f2): } \quad\left(x_{1}, x_{2}\right)=(x, 0), \quad\left(x_{1}^{*}, x_{2}^{*}\right)=\left(0, x^{*}\right), \\
& \text { Pattern (h1-f12): }\left(x_{1}, x_{2}\right)=(x, 0), \quad 0<x_{i}^{*}<x(\text { for } i=1,2) .
\end{aligned}
$$

From the third equation in (12) to which (13) and the above properties are applied, one obtains

$$
\frac{\gamma x^{*}}{x}<\varphi\left(\frac{\theta_{1}}{\theta_{2}}\right) \frac{\theta_{1}}{\theta_{2}^{*}} \text { in pattern (h12-f2), } \quad \frac{\gamma x^{*}}{x}>\varphi\left(\frac{\theta_{1}^{*}}{\theta_{2}^{*}}\right) \frac{\theta_{1}}{\theta_{2}^{*}} \text { in pattern (h1-f12). }
$$

Therefore, with (11) the following lemma obtains:

Lemma 1: As the size of the foreign employed relative to the home employed, $\gamma x^{*} / x$, increases, the three specialization patterns consecutively appear:

$$
\frac{\gamma x^{*}}{x}<\varphi\left(\frac{\theta_{1}}{\theta_{2}}\right) \frac{\theta_{1}}{\theta_{2}^{*}} \Rightarrow \text { Pattern (h12-f2): } \omega=\frac{\theta_{1}}{\theta_{2}}, \quad w=p_{1}\left(\frac{\theta_{1}}{\theta_{2}}\right) \theta_{1}, \quad w^{*}=p_{2}\left(\frac{\theta_{1}}{\theta_{2}}\right) \theta_{2}^{*} .
$$




$$
\begin{gathered}
\varphi\left(\frac{\theta_{1}}{\theta_{2}}\right) \frac{\theta_{1}}{\theta_{2}^{*}}<\frac{\gamma x^{*}}{x}<\varphi\left(\frac{\theta_{1}^{*}}{\theta_{2}^{*}}\right) \frac{\theta_{1}}{\theta_{2}^{*}} \Rightarrow \text { Pattern (h1-f2): } \frac{\gamma x^{*}}{x}=\varphi(\omega) \frac{\theta_{1}}{\theta_{2}^{*}}, \quad \frac{\theta_{1}}{\theta_{2}}>\omega>\frac{\theta_{1}^{*}}{\theta_{2}^{*}}, \\
w=p_{1}(\omega) \theta_{1}, \quad w^{*}=p_{2}(\omega) \theta_{2}^{*}, \\
\frac{\gamma x^{*}}{x}>\varphi\left(\frac{\theta_{1}^{*}}{\theta_{2}^{*}}\right) \frac{\theta_{1}}{\theta_{2}^{*}} \Rightarrow \text { Pattern (h1-f12): } \omega=\frac{\theta_{1}^{*}}{\theta_{2}^{*}}, \quad w=p_{1}\left(\frac{\theta_{1}^{*}}{\theta_{2}^{*}}\right) \theta_{1}, \quad w^{*}=p_{2}\left(\frac{\theta_{1}^{*}}{\theta_{2}^{*}}\right) \theta_{2}^{*} .
\end{gathered}
$$

The implication of lemma 1 is straightforward. The country with much more people working produces both commodities while the other specializes in the commodity with comparative advantage. Therefore, the relative price equals the autarky level of the country that produces both commodities. If the number of the employed is similar between the two countries, both countries specialize in respective commodities with comparative advantage.

In the home and foreign money markets real money balances $m^{(*)}$ satisfy

$$
m^{(*)}=\frac{M^{(*)}}{P^{(*)}}
$$

where $M^{(*)}$ is each country's nominal money supply per capita, which is assumed to be constant over time, for simplicity. Time differentiation of the equation yields

$$
\dot{m}^{(*)}=-\pi^{(*)} m^{(*)}
$$

The flow budget equation in (7) to which $w^{(*)}$ in lemma 1 and $\dot{m}^{(*)}$ in (14) are applied turns to

$$
\begin{gathered}
\dot{b}=\rho b+p_{1}(\omega) \theta_{1} x-c, \\
\dot{b}^{*}=\rho b^{*}+p_{2}(\omega) \theta_{2}^{*} x^{*}-c^{*},
\end{gathered}
$$

which are the two countries’ current account equations, respectively. International lending and borrowing $b$ and $b^{*}$ always satisfy

$$
b+\gamma b^{*}=0
$$

where $\gamma=L^{*} / L$. The absolute values of $b$ and $b^{*}$ are assumed to be negligibly small so that one can ignore the redistribution effect of a change in population on foreign assets or debts among people within a country. The case where $b$ and $b^{*}$ are non-negligible is discussed in section 6 . 
Because the two countries have the same subjective discount rate $\rho$, one find the following property, of which the proof is set out in Appendix A.

Lemma 2: The economy immediately jumps to the steady state where $r$ equals $\rho$, the current account $\dot{b}\left(=-\dot{b}^{*}\right)$ equals zero, and real wages and consumption are constant, satisfying

$$
c=\rho b+p_{1}(\omega) \theta_{1} x, \quad c^{*}=\rho b^{*}+p_{2}(\omega) \theta_{2}^{*} x^{*} .
$$

\section{The relative population size, employment and consumption}

Having set up the model, let us find the relationship between the relative population size and the two countries' employment and consumption. This section first treats the benchmark case where full employment prevails in both countries, and shows the condition under which full employment cannot be achieved and secular stagnation of aggregate demand arises in each country. Then, the cases where one of the two countries or both of them suffer from secular demand stagnation are examined.

\section{4-1. Full employment in both countries}

If both countries achieve full employment:

$$
x=1, x^{*}=1,
$$

from lemmas 1 and 2 one finds

$$
\begin{gathered}
c=\rho b+p_{1}(\omega) \theta_{1}, \quad c^{*}=\rho b^{*}+p_{2}(\omega) \theta_{2}^{*} ; \\
\gamma<\varphi\left(\frac{\theta_{1}}{\theta_{2}}\right) \frac{\theta_{1}}{\theta_{2}^{*}} \rightarrow \text { pattern (h12-f2): } \omega=\frac{\theta_{1}}{\theta_{2}}, \\
\varphi\left(\frac{\theta_{1}}{\theta_{2}}\right) \frac{\theta_{1}}{\theta_{2}^{*}}<\gamma<\varphi\left(\frac{\theta_{1}^{*}}{\theta_{2}^{*}}\right) \frac{\theta_{1}}{\theta_{2}^{*}} \rightarrow \text { pattern (h1-f2): } \quad \gamma=\varphi(\omega) \frac{\theta_{1}}{\theta_{2}^{*}}, \\
\varphi\left(\frac{\theta_{1}^{*}}{\theta_{2}^{*}}\right) \frac{\theta_{1}}{\theta_{2}^{*}}<\gamma \rightarrow \text { pattern (h1-f12): } \quad \omega=\frac{\theta_{1}^{*}}{\theta_{2}^{*}}
\end{gathered}
$$




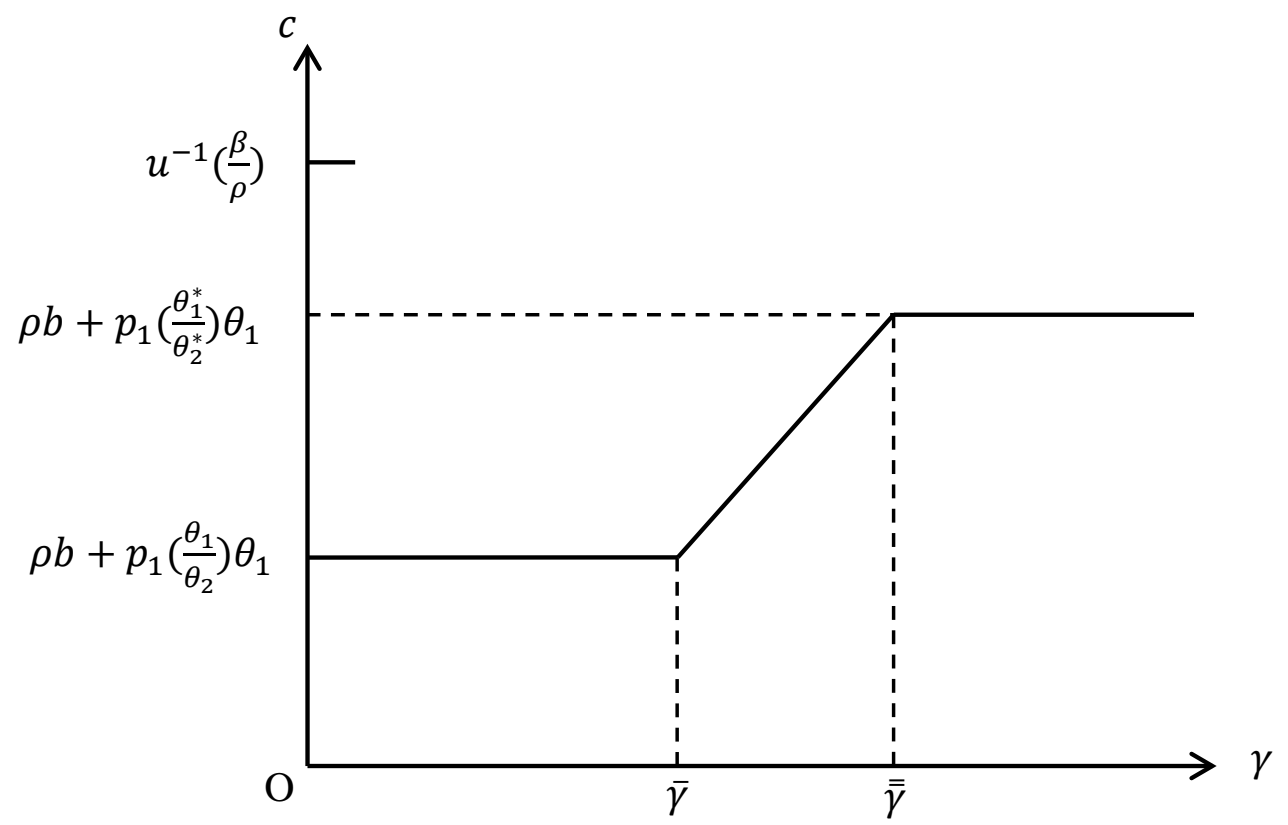

Figure 1: Full employment in the home country

Thus, if the relative foreign population $\gamma$ is low enough, specialization pattern (h12-f2) appears and $\gamma$ affects none of $\omega, c$ and $c^{*}$. If $\gamma$ is between $\varphi\left(\theta_{1} / \theta_{2}\right) \theta_{1} / \theta_{2}^{*}$ and $\varphi\left(\theta_{1}^{*} / \theta_{2}^{*}\right) \theta_{1} / \theta_{2}^{*}$, pattern (f1-h2) appears. Because $p_{1}^{\prime}(\omega)<0$ and $\varphi^{\prime}(\omega)<0$, as shown in (5) and (12) respectively, from (17),

$$
\frac{d \omega}{d \gamma}=\frac{\theta_{2}^{*}}{\varphi \prime(\omega) \theta_{1}}<0, \frac{d c}{d \gamma}=p_{1}^{\prime}(\omega) \theta_{1} \frac{d \omega}{d \gamma}>0, \frac{d c^{*}}{d \gamma}=p_{2}^{\prime}(\omega) \theta_{2}^{*} \frac{d \omega}{d \gamma}<0,
$$

and hence

$$
\gamma \uparrow \rightarrow \omega \downarrow, x=1, c \uparrow, x^{*}=1, c^{*} \downarrow \quad \text { in pattern (f1-h2). }
$$

A larger $\gamma$ increases the ratio of foreign products to home products and lowers the relative price $\omega$ of the foreign commodity. Thus, it improves the home terms of trade and increases $c$ but worsens the foreign terms of trade and decreases $c^{*}$. If $\gamma$ is higher than $\varphi\left(\theta_{1}^{*} / \theta_{2}^{*}\right) \theta_{1} / \theta_{2}^{*}$, pattern (h1-f12) appears and $\omega, c$ and $c^{*}$ stay constant for any $\gamma$.

This relationship between $\gamma$ and $c$ is illustrated in figure 1, where $\bar{\gamma}$ and $\overline{\bar{\gamma}}$ are the critical values of $\gamma$ at which the specialization pattern changes. From (17), they are 


$$
\bar{\gamma}=\varphi\left(\frac{\theta_{1}}{\theta_{2}}\right) \frac{\theta_{1}}{\theta_{2}^{*}}, \quad \overline{\bar{\gamma}}=\varphi\left(\frac{\theta_{1}^{*}}{\theta_{2}^{*}}\right) \frac{\theta_{1}}{\theta_{2}^{*}}
$$

From (9) in which $\pi=0$, and lemma $2, P$ and $P^{*}$ must satisfy

$$
\rho=\frac{v^{\prime}(M / P)}{u^{\prime}(c)}, \quad \rho=\frac{v^{\prime}\left(M^{*} / P^{*}\right)}{u^{\prime}\left(c^{*}\right)}
$$

where $c$ and $c^{*}$ are given in (17). In the presence of a liquidity trap, however, there may be no solutions of $P$ and $P^{*}$. In the present setting a liquidity trap emerges if the marginal utility of money $v^{\prime}(m)$ has a positive lower bound $\beta,{ }^{4}$

$$
v^{\prime}(\infty)=\beta>0
$$

because under this property the home money demand function given in (9) satisfies

$$
R=\frac{v^{\prime}(m)}{u^{\prime}(c)}\left(>\frac{\beta}{u^{\prime}(c)} \text { for any } m\right) .
$$

$R$ remains to be strictly positive as $m$ increases, implying a liquidity trap. ${ }^{5}$

In this case, if and only if the home (or foreign) consumption $c$ (or $c^{*}$ ) given in (17) is so large as to satisfy

$$
\begin{gathered}
\rho \leq \frac{\beta}{u^{\prime}(c)}\left(<\frac{v^{\prime}(M / P)}{u^{\prime}(c)}\right), \quad \text { where } c=\rho b+p_{1}(\omega) \theta_{1}, \\
\rho \leq \frac{\beta}{u^{\prime}\left(c^{*}\right)}\left(<\frac{v^{\prime}\left(M^{*} / P^{*}\right)}{u^{\prime}\left(c^{*}\right)}\right), \quad \text { where } c^{*}=\rho b^{*}+p_{2}(\omega) \theta_{2}^{*},
\end{gathered}
$$

there is no $P$ (or $P^{*}$ ) that satisfies the first (or second) equation in (19), implying that there is no steady state with full employment in the home (or foreign) country. In order for the full-employment steady state to be feasible, the two inequalities in (21) must be invalid.

Given that the left- and right-hand sides of each inequality in (21) respectively represent the time preference rate and the liquidity premium, (21) shows that the marginal desire for

\footnotetext{
${ }^{4}$ The validity of this property is empirically shown by Ono et al. (2004) using both a parametric and a non-parametric approach.

${ }^{5}$ If $v^{\prime}(m)$ continues to be positive as $m$ expands, $v(m)$ does not imply the transaction motive. It should be wealth preference. In Appendix B the wealth preference and the narrowly-defined liquidity preference due to the transaction motive are separately introduced to the present model. It is shown that in this setting the following analysis is still valid while the home nominal interest rate is zero in the steady state.
} 
holding money dominates that for consumption if the household consumes enough to realize full employment. Thus, aggregated demand deficiency and unemployment will appear in the steady state, which will be shown in the following sections. Note that a country with high value productivity, $p_{1} \theta_{1}$ or $p_{2} \theta_{2}^{*}$, is likely to satisfy (21) and suffer from secular stagnation of aggregate demand.

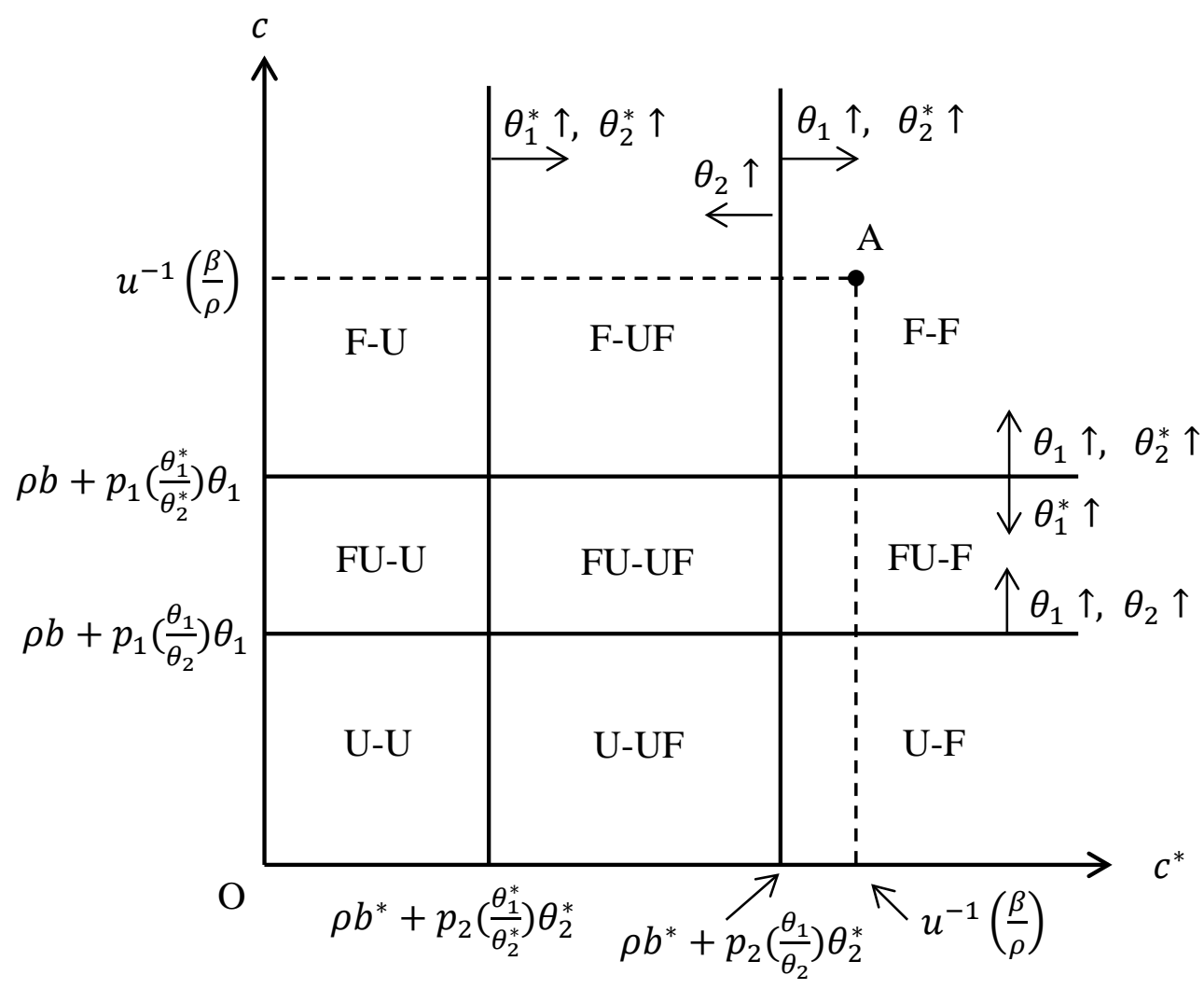

Figure 2: Patterns of full- and underemployment

From (5), (10) and (17), the maximum and minimum values of $c$ and $c^{*}$ under full employment, $c^{M(*)}$ and $c^{m(*)}$ respectively, are

$$
\begin{gathered}
c^{M}=\rho b+p_{1}\left(\frac{\theta_{1}^{*}}{\theta_{2}^{*}}\right) \theta_{1}, \quad c^{m}=\rho b+p_{1}\left(\frac{\theta_{1}}{\theta_{2}}\right) \theta_{1}, \\
c^{M *}=\rho b^{*}+p_{2}\left(\frac{\theta_{1}}{\theta_{2}}\right) \theta_{2}^{*}, \quad c^{m *}=\rho b^{*}+p_{2}\left(\frac{\theta_{1}^{*}}{\theta_{2}^{*}}\right) \theta_{2}^{*} .
\end{gathered}
$$


As shown in figure 2, they partition the positive quadrant of the $\left(c, c^{*}\right)$ plane into nine areas. From (21), full employment consumption $c^{(*)}$ cannot exceed $u^{\prime-1}(\beta / \rho)$. Therefore, full employment always appears and (17) holds when

$$
\text { point A: }\left(c, c^{*}\right)=\left(u^{\prime-1}\left(\frac{\beta}{\rho}\right), u^{\prime-1}\left(\frac{\beta}{\rho}\right)\right) \text {, }
$$

is located in F-F of figure 2. From (5), $c^{M(*)}$ and $c^{m(*)}$ given above satisfy

$$
\begin{aligned}
& \theta_{1} \uparrow \rightarrow c^{M} \uparrow, c^{m} \uparrow, c^{M *} \uparrow ; \quad \theta_{2} \uparrow \rightarrow c^{m} \uparrow, c^{M *} \downarrow ; \\
& \theta_{1}^{*} \uparrow \rightarrow c^{M} \downarrow, c^{m *} ; ; \quad \theta_{2}^{*} \uparrow \rightarrow c^{M} \uparrow, c^{M *} \uparrow, c^{m *} \uparrow ;
\end{aligned}
$$

i.e., changes in the productivity parameters, $\theta_{1}^{(*)}$ and $\theta_{2}^{(*)}$, move the boundary curves and locate point A defined by (22) in different areas. $\mathrm{F}$ and $\mathrm{U}$ in the area names imply full employment and underemployment in each country, respectively.

In the following the condition under which $\mathrm{A}$ is located in each area is found and the relationship between the relative population size and the two countries' specialization patterns, consumption and employment in each case is examined.

\section{4-2. Case U-U}

If $\theta_{1}$ and $\theta_{2}^{*}$ are so large that point $A$ given by (22) is located in $\mathrm{U}-\mathrm{U}$ of figure 2, where

$$
u^{\prime-1}\left(\frac{\beta}{\rho}\right)<\min .\left(\rho b+p_{1}\left(\frac{\theta_{1}}{\theta_{2}}\right) \theta_{1}, \rho b^{*}+p_{2}\left(\frac{\theta_{1}^{*}}{\theta_{2}^{*}}\right) \theta_{2}^{*}\right)
$$

the two inequalities in (21) hold for any $\omega \in\left[\theta_{1}^{*} / \theta_{2}^{*}, \theta_{1} / \theta_{2}\right]$. The marginal desire for holding money dominates that for consumption in both countries and aggregate demand deficiency appears. In order to treat aggregate demand deficiency, a wage adjustment mechanism that can accommodate labor demand shortages must be assumed. Moreover, it should not intrinsically avoid the possibility of full employment because the present unemployment is caused not by wage sluggishness but by aggregate demand deficiency. 
To describe sluggish wage adjustment the Calvo pricing is widely adopted in DSGE models. However, it never allows any demand-supply discrepancy to appear either during the adjustment process or in the steady state. The search theory (e.g. Pissarides, 2000) explains unemployment but, in turn, never allows full employment to be reached. Moreover, the unemployment that it discusses is of the frictional type. Thus, neither of them can apply to analyze involuntary unemployment due to aggregate demand deficiency.

Ono and Ishida (2014) extend the Akerlof-type fair wage model (see Akerlof, 1982, and Akerlof and Yellen, 1990) to a dynamic context and present a wage adjustment mechanism that can apply to both the cases of full employment and underemployment. They show that it asymptotically reaches the conventional Walrasian adjustment if unemployment appears in the steady state and is perfect if full employment prevails. Therefore, for simplicity, it is now assumed that home and foreign nominal wages adjust as follows:

$$
\frac{\dot{W}^{(*)}}{W^{(*)}}=\alpha\left(x^{(*)}-1\right)
$$

in the presence of unemployment. ${ }^{6}$ Because $\omega$ is constant in the steady state, from (11) real wage $w^{(*)}$ is constant and hence the wage adjustment given above yields

$$
\pi^{(*)}=\frac{\dot{W}^{(*)}}{W^{(*)}}=\alpha\left(x^{(*)}-1\right)
$$

By substituting (20) and (23) to (9) one finds that if (21) is valid, $c^{(*)}$ in the steady state with aggregate demand deficiency is expressed as a function of $x^{(*)}$ :

$$
\begin{gathered}
\frac{\beta}{u^{\prime}\left(c^{(*)}\right)}=\rho+\alpha\left(x^{(*)}-1\right) \rightarrow c^{(*)}=c\left(x^{(*)}\right) \equiv u^{\prime-1}\left(\frac{\beta}{\rho+\alpha\left(x^{(*)}-1\right)}\right), \\
c^{\prime}\left(x^{(*)}\right)>0, \quad x^{(*)}<1 .
\end{gathered}
$$

Because $c^{(*)}$ given in lemma 2 satisfies (24) in the present case, $x^{(*)}$ satisfies

$$
c(x)=\rho b+p_{1}(\omega) \theta_{1} x, \quad c\left(x^{*}\right)=\rho b^{*}+p_{2}(\omega) \theta_{2}^{*} x^{*},
$$

\footnotetext{
${ }^{6}$ Schmitt-Grohé and Uribe (2016, 2017) assume basically the same wage adjustment mechanism.
} 


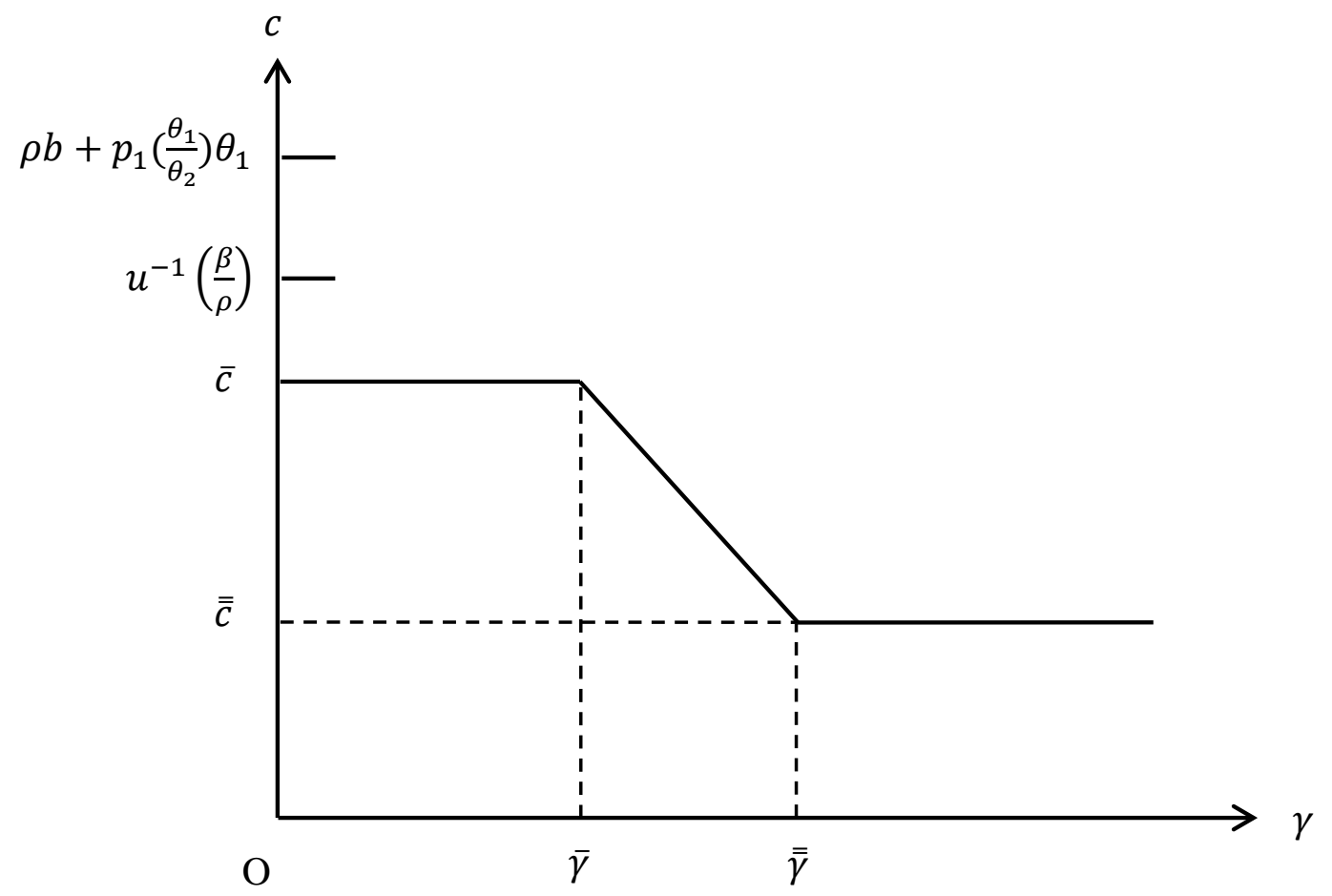

Figure 3: Underemployment in the home country

where from (12) and lemma $2 \omega$ satisfies

$$
\begin{aligned}
& \frac{\gamma x^{*}}{x}<\varphi\left(\frac{\theta_{1}}{\theta_{2}}\right)\left(\frac{\theta_{1}}{\theta_{2}^{*}}\right) \rightarrow \text { pattern (h12-f2): } \omega=\frac{\theta_{1}}{\theta_{2}}, \\
& \varphi\left(\frac{\theta_{1}}{\theta_{2}}\right)\left(\frac{\theta_{1}}{\theta_{2}^{*}}\right)<\frac{\gamma x^{*}}{x}<\varphi\left(\frac{\theta_{1}^{*}}{\theta_{2}^{*}}\right)\left(\frac{\theta_{1}}{\theta_{2}^{*}}\right) \rightarrow \text { pattern (h1-f2): } \\
& \quad \frac{\gamma x^{*}}{x}=\varphi(\omega)\left(\frac{\theta_{1}}{\theta_{2}^{*}}\right), \quad c(x)+\gamma c\left(x^{*}\right)=\frac{p_{1}(\omega) \theta_{1} x}{\delta(\omega)} \Rightarrow x^{(*)}=\hat{x}^{(*)}(\omega, \gamma), \\
& \varphi\left(\frac{\theta_{1}^{*}}{\theta_{2}^{*}}\right)\left(\frac{\theta_{1}}{\theta_{2}^{*}}\right)<\frac{\gamma x^{*}}{x} \rightarrow \text { pattern (h1-f12): } \omega=\frac{\theta_{1}^{*}}{\theta_{2}^{*}} .
\end{aligned}
$$

Thus, $c^{(*)}, x^{(*)}$ and $\omega$ are fully determined. A change in $\gamma$ does not affect the variables in pattern (h12-f2) or (h1-f12), while in pattern (h1-f2) it varies them as follows:

$$
\gamma \uparrow \rightarrow \omega \downarrow, \quad x \downarrow, c \downarrow, \quad x^{*} \uparrow, \quad c^{*} \uparrow, \quad \frac{\gamma x^{*}}{x} \uparrow \quad \text { in pattern (h1-f2), }
$$

of which the proof is set out in appendix C. An increase in the relative foreign population $\gamma$ expands the production ratio of commodity 2 to commodity 1 , which reduces $p_{2}(\omega)$ and raises 
$p_{1}(\omega)$. Thus, world demand for commodity 1 declines, which reduces home employment $x$ and consumption $c$. World demand for commodity 2 expands and hence foreign employment $x^{*}$ and consumption $c^{*}$ increase. The last property in (27) and lemma 1 imply the three specialization patterns to appear consecutively as $\gamma$ increases.

From (25) and (26), $c$ in patterns (h12-f2) and (h1-f12), respectively denoted by $\bar{c}$ and $\overline{\bar{c}}$, and the critical values of $\gamma$ that separate the three specialization patterns, $\bar{\gamma}$ and $\overline{\bar{\gamma}}$, satisfy

$$
\begin{aligned}
& \bar{c}=c(\bar{x})=\rho b+p_{1}\left(\frac{\theta_{1}}{\theta_{2}}\right) \theta_{1} \bar{x}, \quad \bar{\gamma}=\bar{\gamma}_{U U} \text { where } \bar{x}=\hat{x}\left(\frac{\theta_{1}}{\theta_{2}}, \bar{\gamma}_{U U}\right), \\
& \overline{\bar{c}}=c(\overline{\bar{x}})=\rho b+p_{1}\left(\frac{\theta_{1}^{*}}{\theta_{2}^{*}}\right) \theta_{1} \overline{\bar{x}}, \quad \overline{\bar{\gamma}}=\overline{\bar{\gamma}}_{U U} \text { where } \overline{\bar{x}}=\hat{x}\left(\frac{\theta_{1}^{*}}{\theta_{2}^{*}}, \overline{\bar{\gamma}}_{U U}\right) .
\end{aligned}
$$

Figure 3 shows $c$ as a function of $\gamma$, where $\bar{c}, \overline{\bar{c}}, \bar{\gamma}$ and $\overline{\bar{\gamma}}$ are given by (28).

\section{4-3. Case U-F}

In the case where point $\mathrm{A}$ is located in U-F of figure 2 -i.e.,

$$
\rho b+p_{1}\left(\frac{\theta_{1}}{\theta_{2}}\right) \theta_{1}>u^{-1}\left(\frac{\beta}{\rho}\right)>\rho b^{*}+p_{2}\left(\frac{\theta_{1}}{\theta_{2}}\right) \theta_{2}^{*},
$$

which appears when $\theta_{1}$ is large and $\theta_{2}^{*}$ is small, the foreign country always achieves full employment because the second inequality in (21) is invalid for any $\omega \in\left[\theta_{1}^{*} / \theta_{2}^{*}, \theta_{1} / \theta_{2}\right]$. The home country cannot attain full employment and suffers from secular stagnation because the first inequality in (21) is valid for any $\omega \in\left[\theta_{1}^{*} / \theta_{2}^{*}, \theta_{1} / \theta_{2}\right]$, implying that the marginal desire for holding money dominates that for consumption. Therefore,

$$
x<1, \quad x^{*}=1
$$

and then from lemmas 1 and 2 and function $c(x)$ given by (24), $\omega, c, c^{*}$ and $x$ satisfy

$$
\begin{gathered}
c=c(x)=\rho b+p_{1}(\omega) \theta_{1} x, \quad c^{*}=\rho b^{*}+p_{2}(\omega) \theta_{2}^{*} ; \\
\frac{\gamma}{x}<\varphi\left(\frac{\theta_{1}}{\theta_{2}}\right) \frac{\theta_{1}}{\theta_{2}^{*}} \rightarrow \text { pattern (h12-f2): } \omega=\frac{\theta_{1}}{\theta_{2}}, \\
\varphi\left(\frac{\theta_{1}}{\theta_{2}}\right) \frac{\theta_{1}}{\theta_{2}^{*}}<\frac{\gamma}{x}<\varphi\left(\frac{\theta_{1}^{*}}{\theta_{2}^{*}}\right) \frac{\theta_{1}}{\theta_{2}^{*}} \rightarrow \text { pattern (h1-f2): } x=\left(\frac{\theta_{2}^{*}}{\theta_{1}}\right) \frac{\gamma}{\varphi(\omega)},
\end{gathered}
$$




$$
\varphi\left(\frac{\theta_{1}^{*}}{\theta_{2}^{*}}\right) \frac{\theta_{1}}{\theta_{2}^{*}}<\frac{\gamma}{x} \rightarrow \text { pattern (h1-f12): } \omega=\frac{\theta_{1}^{*}}{\theta_{2}^{*}}
$$

From (29), neither $x$ nor $c(x)$ depends on $\gamma$ in patterns (h12-f2) and (h1-f12) while both of them do in pattern (h1-f2).

From (15), (24), lemma 2 and $x$ in pattern (h1-f2) of (29),

$$
\dot{b}=\rho b+p_{1}(\omega) \theta_{1} x-c(x)=0, \quad x=\left(\frac{\theta_{2}^{*}}{\theta_{1}}\right) \frac{\gamma}{\varphi(\omega)} .
$$

By assuming $\dot{b}$ to satisfy the Marshall-Lerner condition $\dot{b}_{\omega}>0$ and using $p_{1}^{\prime}(\omega)<0$ in (5) and $\varphi^{\prime}<0$ in (12), one obtains

$$
\begin{gathered}
\dot{b}_{\omega}\left(\equiv \frac{\partial \dot{b}}{\partial \omega}\right)=p_{1}^{\prime}(\omega) \theta_{1} x-\left[p_{1}(\omega) \theta_{1}-c^{\prime}(x)\right] \frac{x \varphi^{\prime}}{\varphi}>0, \\
\dot{b}_{\gamma}=\left[p_{1}(\omega) \theta_{1}-c^{\prime}(x)\right] \frac{x}{\gamma}>0,
\end{gathered}
$$

where the latter property implies

$$
p_{1}(\omega) \theta_{1}-c^{\prime}(x)>0
$$

In appendix $C$ it is shown that the property of $(31)$ must hold if $x$ exists within $(0,1)$. Totally differentiating the two equations in (30) and applying the above properties of $\dot{b}_{\omega}$ and $\dot{b}_{\gamma}$ to the results yields

$$
\frac{d \omega}{d \gamma}=-\frac{\dot{b}_{\gamma}}{\dot{b}_{\omega}}<0, \quad \frac{d x}{d \gamma}=\frac{p_{1}^{\prime}(\omega) \theta_{1} x^{2}}{\gamma \dot{b}_{\omega}}<0, \quad \frac{d\left(\frac{\gamma}{x}\right)}{d \gamma}>0
$$

in pattern (h1-f2).

The implication is the following. Because a larger $\gamma$ increases foreign supply of commodity 2, lowers $\omega$ and raises $p_{1}(\omega)$, home current account $\dot{b}$ in (30) improves if $x$ is invariant. Therefore, in order for the current account to deteriorate and recover the balance, from (31) $x$ has to be smaller than before. A smaller $x$ worsens deflation and urges home households to decrease consumption $c$, as shown by (24). The decrease in $\omega$ in turn deteriorates the foreign terms of trade and reduces foreign consumption $c^{*}$ given in (29). Therefore, 


$$
\gamma \uparrow \rightarrow \omega \downarrow, x \downarrow, c \downarrow, x^{*}=1, c^{*} \downarrow, \frac{\gamma}{x} \uparrow \quad \text { in pattern (f1-h2). }
$$

Because $\gamma / x$ increases with $\gamma$, as shown above, from lemma 1 the three specialization patterns consecutively appear as $\gamma$ increases.

From (29), the maximum and minimum values of $c$ and the boundary levels of $\gamma$ satisfy

$$
\begin{array}{ll}
\bar{\gamma}=\bar{\gamma}_{U F} \equiv\left(\frac{\theta_{1}}{\theta_{2}^{*}}\right) \bar{x} \varphi\left(\frac{\theta_{1}}{\theta_{2}}\right), \quad \bar{c}=c(\bar{x})=\rho b+p_{1}\left(\frac{\theta_{1}}{\theta_{2}}\right) \theta_{1} \bar{x}, \\
\overline{\bar{\gamma}}=\overline{\bar{\gamma}}_{U F} \equiv\left(\frac{\theta_{1}}{\theta_{2}^{*}}\right) \overline{\bar{x}} \varphi\left(\frac{\theta_{1}^{*}}{\theta_{2}^{*}}\right), \quad \overline{\bar{c}}=c(\overline{\bar{x}})=\rho b+p_{1}\left(\frac{\theta_{1}^{*}}{\theta_{2}^{*}}\right) \theta_{1} \overline{\bar{x}} .
\end{array}
$$

Note that $\bar{c}$ and $\overline{\bar{c}}$ are equal to, but $\bar{\gamma}$ and $\overline{\bar{\gamma}}$ are different from, those in the case where both countries are underemployed, given in (28). Therefore, the shape of $c$ as a function of $\gamma$ is not exactly the same as, but quite similar to, that in figure 3 .

\section{4-4. Case F-U}

In the case where point $\mathrm{A}$ is located in F-U of figure 2:

$$
\rho b^{*}+p_{2}\left(\frac{\theta_{1}}{\theta_{2}}\right) \theta_{2}^{*}>u^{-1}\left(\frac{\beta}{\rho}\right)>\rho b+p_{1}\left(\frac{\theta_{1}^{*}}{\theta_{2}^{*}}\right) \theta_{1},
$$

which emerges when $\theta_{1}$ is small and $\theta_{2}^{*}$ is large, is symmetric to the previous case where point A is located in U-F. The home country attains full employment while the foreign country suffers from underemployment. Therefore, by interchanging the home variables and the foreign ones in (29) and (32) and rearranging the results one obtains

$$
\begin{gathered}
c=\rho b+p_{1}(\omega) \theta_{1}, \quad c^{*}=c\left(x^{*}\right)=\rho b^{*}+p_{2}(\omega) \theta_{2}^{*} x^{*} ; \\
\gamma x^{*}<\varphi\left(\frac{\theta_{1}}{\theta_{2}}\right) \frac{\theta_{1}}{\theta_{2}^{*}} \rightarrow \text { pattern (h12-f2): } \omega=\frac{\theta_{1}}{\theta_{2}}, \\
\varphi\left(\frac{\theta_{1}}{\theta_{2}}\right) \frac{\theta_{1}}{\theta_{2}^{*}}<\gamma x^{*}<\varphi\left(\frac{\theta_{1}^{*}}{\theta_{2}^{*}}\right) \frac{\theta_{1}}{\theta_{2}^{*}} \rightarrow \text { pattern (h1-f2): } \gamma=\frac{\theta_{1} \varphi(\omega)}{\theta_{2}^{*} x^{*}}, \\
\gamma \uparrow \rightarrow \omega \downarrow, \quad x=1, c \uparrow, \quad x^{*} \uparrow, \quad c^{*} \uparrow, \gamma x^{*} \uparrow, \\
\varphi\left(\frac{\theta_{1}^{*}}{\theta_{2}^{*}}\right) \frac{\theta_{1}}{\theta_{2}^{*}}<\gamma x^{*} \rightarrow \text { pattern (h1-f12): } \omega=\frac{\theta_{1}^{*}}{\theta_{2}^{*} .}
\end{gathered}
$$


The relationship between $\gamma$ and $c$ obtained above is similar to that in figure 1 . By interchanging the home variables and the foreign ones in (33) one obtains $\bar{\gamma}$ and $\overline{\bar{\gamma}}$, the critical values of $\gamma$ that separate the three specialization patterns, in the present case. They satisfy

$$
\begin{aligned}
& \bar{\gamma}=\bar{\gamma}_{F U} \equiv \frac{\theta_{1} \varphi\left(\frac{\theta_{1}}{\theta_{2}}\right)}{\theta_{2}^{*} \bar{x}^{*}} \quad \text { where } c\left(\bar{x}^{*}\right)=\rho b^{*}+p_{2}\left(\frac{\theta_{1}}{\theta_{2}}\right) \theta_{2}^{*} \bar{x}^{*}, \\
& \overline{\bar{\gamma}}=\overline{\bar{\gamma}}_{F U} \equiv \frac{\theta_{1} \varphi\left(\frac{\theta_{1}^{*}}{\theta_{2}^{*}}\right)}{\theta_{2}^{*} \overline{\bar{x}}^{*}} \quad \text { where } \quad c\left(\overline{\bar{x}}^{*}\right)=\rho b^{*}+p_{2}\left(\frac{\theta_{1}^{*}}{\theta_{2}^{*}}\right) \theta_{2}^{*} \overline{\bar{x}}^{*}
\end{aligned}
$$

\section{4-5. Summary of this section}

The results of this section are thus summarized by the following two propositions:

Proposition 1: A country with high value productivity suffers from secular aggregate demand stagnation and underemployment whereas a country with low value productivity attains full employment.

Proposition 2: If a country has a much larger population than the other, it produces both commodities while the smaller country specializes in the sector with comparative advantage. The relative price, home and foreign consumption and employment are constant with changes in the international population ratio. If the populations of the two countries are similar, both countries perfectly specialize according to respective comparative advantages. Then, whether the foreign country is fully employed or underemployed, a larger foreign population or a smaller home population makes lower the relative price of the foreign commodity. Accordingly, home consumption increases if the home country is fully employed, whereas home employment and consumption decrease if 
it is underemployed. Foreign consumption decreases if the foreign country is fully employed, whereas foreign employment and consumption increase if it is underemployed.

\section{Switching between full employment and underemployment}

The previous section has treated the cases in which each country does not switch between full employment and underemployment. This section examines the cases in which one or both countries switch between the two as the relative population $\gamma$ changes.

\section{5-1. Case FU-F}

In the case where point A defined in (22) is located in FU-F of figure 2, where

$$
\rho b+p_{1}\left(\frac{\theta_{1}^{*}}{\theta_{2}^{*}}\right) \theta_{1}>u^{\prime-1}\left(\frac{\beta}{\rho}\right)>\rho b+p_{1}\left(\frac{\theta_{1}}{\theta_{2}}\right) \theta_{1}, \quad u^{\prime-1}\left(\frac{\beta}{\rho}\right)>\rho b^{*}+p_{2}\left(\frac{\theta_{1}}{\theta_{2}}\right) \theta_{2}^{*},
$$

the foreign country always achieves full employment, while the home country attains full employment when $c$ is small and faces underemployment when $c$ is large.

More precisely, when $\gamma$ is smaller than $\varphi\left(\theta_{1} / \theta_{2}\right) \theta_{1} / \theta_{2}^{*}$, all properties in case F-F are valid. Then, from (17),

$$
c=\rho b+p_{1}\left(\theta_{1} / \theta_{2}\right) \theta_{1}, \quad c^{*}=\rho b^{*}+p_{2}\left(\theta_{1} / \theta_{2}\right) \theta_{2}^{*},
$$

and hence the two inequalities in (21) are invalid, implying that the steady state with full employment is reached in both countries.

When $\gamma$ is higher than $\varphi\left(\theta_{1} / \theta_{2}\right) \theta_{1} / \theta_{2}^{*}$, pattern (h1-f2) in (17) appears and $c$ increases with $\gamma$, as shown by (18), through an improvement in the home terms of trade. Once $c$ reaches the upper bound $u^{\prime-1}(\beta / \rho)$, which occurs when $\gamma=\gamma_{c}$ that satisfies

$$
\gamma_{c}=\varphi\left(\omega_{c}\right)\left(\frac{\theta_{1}}{\theta_{2}^{*}}\right) \text { where } c=\rho b+p_{1}\left(\omega_{c}\right) \theta_{1}=u^{\prime-1}\left(\frac{\beta}{\rho}\right) \text {, }
$$




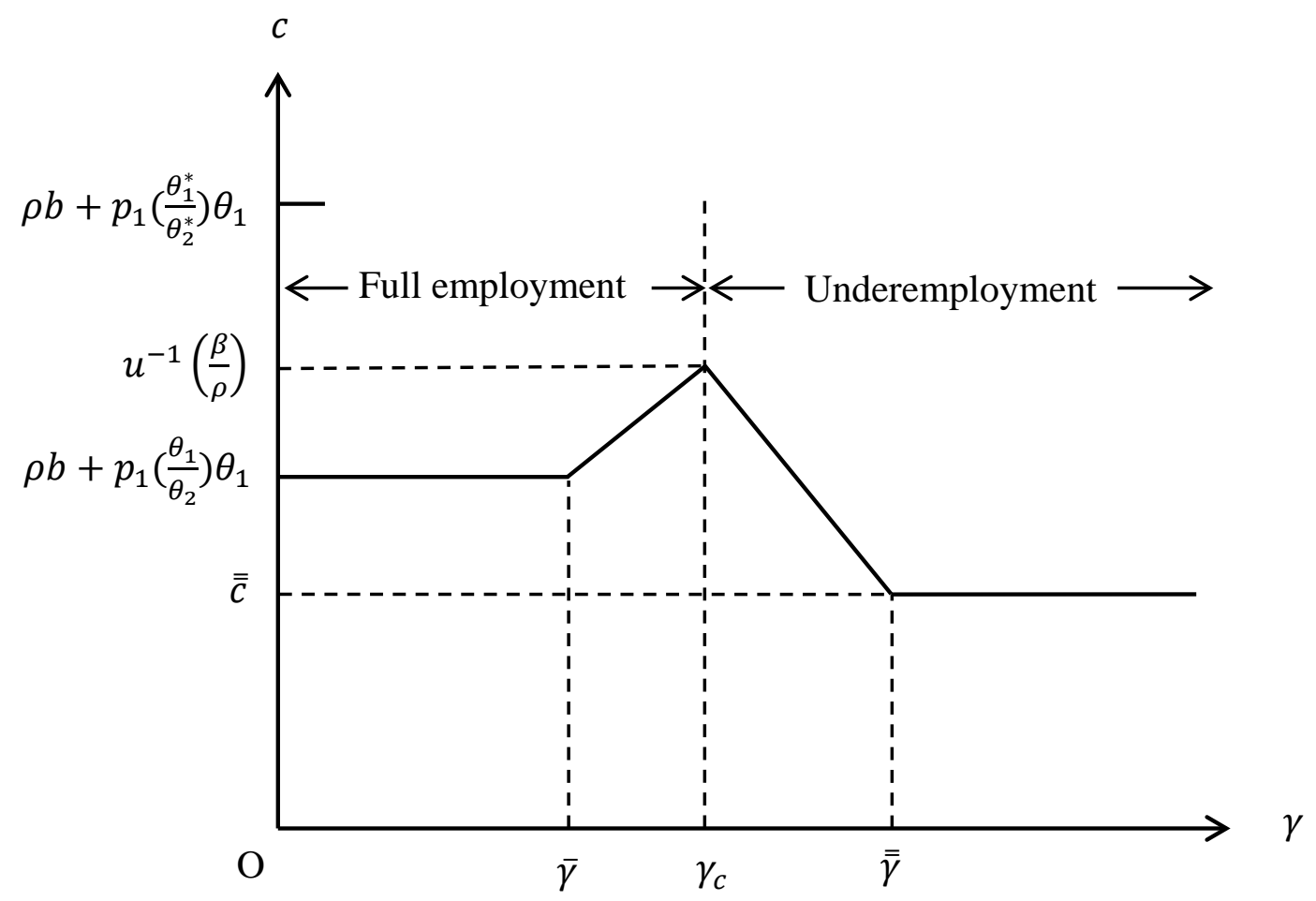

Figure 4: Switch from full employment to underemployment

as is clear from (17), a further increase in $\gamma$ makes this $c$ so large as to satisfy the first inequality in (21). Then, the home country suffers from underemployment while the foreign country maintains full employment, making case U-F to appear. Therefore, from (32), an increase in $\gamma$ raises the relative price of the home commodity, worsens home employment and reduces $c$ as far as $\gamma$ is smaller than $\overline{\bar{\gamma}}_{U F}$ given in (33).

For any $\gamma>\overline{\bar{\gamma}}_{U F}$, the international relative commodity price equals the foreign autarky price $\theta_{1}^{*} / \theta_{2}^{*}$ and $c$ is constant at $\overline{\bar{c}}$ given in (33).

Figure 4 illustrates the abovementioned relationship between $\gamma$ and $c$, where $\bar{\gamma}$ equals $\varphi\left(\theta_{1} / \theta_{2}\right) \theta_{1} / \theta_{2}^{*}, \overline{\bar{\gamma}}$ equals $\overline{\bar{\gamma}}_{U F}$ in (33) and $\gamma_{c}$ is given by (36). Because $\omega$ anyway declines and the foreign terms of trade deteriorates as $\gamma$ is larger, $c^{*}$ given in (29) decreases. Therefore, it 
will never make the second inequality in (21) valid and the foreign country always achieves full employment.

\section{5-2. Case F-UF}

In the case where point $\mathrm{A}$ is located in F-UF, where

$$
u^{\prime-1}\left(\frac{\beta}{\rho}\right)>\rho b+p_{1}\left(\frac{\theta_{1}^{*}}{\theta_{2}^{*}}\right) \theta_{1}, \quad \rho b^{*}+p_{2}\left(\frac{\theta_{1}}{\theta_{2}}\right) \theta_{2}^{*}>u^{\prime-1}\left(\frac{\beta}{\rho}\right)>\rho b^{*}+p_{2}\left(\frac{\theta_{1}^{*}}{\theta_{2}^{*}}\right) \theta_{2}^{*},
$$

the home country always achieves full employment. As $\gamma$ increases and $\omega$ declines, the foreign country initially suffers from underemployment, which is the same as in case F-U, but eventually attains full employment, which is the same as in case F-F. This is because the decline in $\omega$ lowers foreign potential income and makes foreign consumption $c^{*}$ lower than the upper bound $u^{\prime-1}(\beta / \rho)$, leading the foreign country from underemployment to full employment. Because the home country always achieves full employment, from proposition 2 a rise in the relative price of the home commodity due to an increase in $\gamma$ makes consumption $c$ larger in pattern (h1-f2), whether the foreign country is fully employed or underemployed. From (17) in case F-F and (34) in case F-U, the minimum and maximum values of $c$ are respectively $\rho b+p_{1}\left(\theta_{1} / \theta_{2}\right)$ and $\rho b+p_{1}\left(\theta_{1}^{*} / \theta_{2}^{*}\right) \theta_{1}$. Thus, the relationship between $\gamma$ and $c$ is similar to that in figure 1 , although $\bar{\gamma}$ equals $\bar{\gamma}_{F U}$ in (35) and $\overline{\bar{\gamma}}$ equals $\varphi\left(\theta_{1}^{*} / \theta_{2}^{*}\right) \theta_{1} / \theta_{2}^{*}$, as shown in (17).

\section{5-3. Case FU-U}

In the case where point $\mathrm{A}$ is located in FU-U of figure 2, where

$$
\rho b+p_{1}\left(\frac{\theta_{1}^{*}}{\theta_{2}^{*}}\right) \theta_{1}>u^{\prime-1}\left(\frac{\beta}{\rho}\right)>\rho b+p_{1}\left(\frac{\theta_{1}}{\theta_{2}}\right) \theta_{1}, \quad \rho b^{*}+p_{2}\left(\frac{\theta_{1}}{\theta_{2}}\right) \theta_{2}^{*}>u^{\prime-1}\left(\frac{\beta}{\rho}\right),
$$


the foreign country is always underemployed because the lowest full employment consumption $\rho b^{*}+p_{2}\left(\theta_{1} / \theta_{2}\right) \theta_{2}^{*}$ exceeds the upper bound $u^{\prime-1}(\beta / \rho)$. The home country attains full employment (case F-U) when $\gamma$ is small and faces underemployment (case $\mathrm{U}-\mathrm{U}$ ) when $\gamma$ is large. Because (34) holds in case F-U, $c$ equals $\rho b+p_{1}\left(\theta_{1} / \theta_{2}\right) \theta_{1}$ when $\gamma$ is smaller than $\bar{\gamma}_{F U}$ given in (35).

When $\gamma>\bar{\gamma}_{F U}$, a larger $\gamma$ raises the relative price of the home commodity, and hence the full-employment level of $c$ increases toward its upper bound $u^{\prime-1}(\beta / \rho)$, as shown in (34). Because the foreign country is underemployed and $c^{*}$ given in lemma 2 satisfies (24), when $c$ reaches $u^{\prime-1}(\beta / \rho), \gamma$ equals $\gamma_{c}^{\prime}$ that satisfies

$$
\gamma_{c}^{\prime}=\frac{\theta_{1} \varphi\left(\omega_{c}\right)}{\theta_{2}^{*} x^{*}}, \quad c=\rho b+p_{1}\left(\omega_{c}\right) \theta_{1}=u^{\prime-1}\left(\frac{\beta}{\rho}\right), \quad c\left(x^{*}\right)=\rho b^{*}+p_{2}\left(\omega_{c}\right) \theta_{2}^{*} x^{*},
$$

where $\omega_{c}$ is the same as that in (36) while $\gamma_{c}^{\prime}$ differs from $\gamma_{c}$ in (36). When $\gamma>\gamma_{c}^{\prime}$, both countries suffer from underemployment, which is the same as in case U-U. Therefore, from (27) an increase in $\gamma$ worsens home employment by raising the relative price of the home commodity $1 / \omega$ and lowers $c$. Once $\gamma$ reaches $\overline{\bar{\gamma}}_{U U}$ given in (28), a further rise in $\gamma$ does not affect $\omega$ and $c$ stays equal to $c(\overline{\bar{x}})$ given in (28). Thus, the $c$ function has a similar shape as illustrated in figure 4 with $\gamma_{c}$ replaced by $\gamma_{c}^{\prime}$.

\section{5-4. Case U-UF}

In the case where point $A$ is located in U-UF of figure 2, where

$$
\rho b+p_{1}\left(\frac{\theta_{1}}{\theta_{2}}\right) \theta_{1}>u^{\prime-1}\left(\frac{\beta}{\rho}\right), \quad \rho b^{*}+p_{2}\left(\frac{\theta_{1}}{\theta_{2}}\right) \theta_{2}^{*}>u^{\prime-1}\left(\frac{\beta}{\rho}\right)>\rho b^{*}+p_{2}\left(\frac{\theta_{1}^{*}}{\theta_{2}^{*}}\right) \theta_{2}^{*},
$$

the home country always suffers from underemployment while the foreign country is underemployed (case U-U) when $\gamma$ is small but fully employed (case U-F) when $\gamma$ is large. From proposition 1, whether the foreign country is fully employed or underemployed, a larger $\gamma$ raises the relative price of the home commodity and hence decreases home employment $x$ 
and consumption $c$ if the home country is underemployed in pattern (h1-f2). Thus, the $c$ function has a similar shape as illustrated in figure 3, where $\bar{\gamma}=\bar{\gamma}_{U U}$ given in (28), which is valid in case $\mathrm{U}-\mathrm{U}$, and $\overline{\bar{\gamma}}=\overline{\bar{\gamma}}_{U F}$ given in (33), which is valid in case U-F.

\section{5-5. Case FU-UF}

Finally, in the case where point $\mathrm{A}$ is located in FU-UF, where

$$
\begin{gathered}
\rho b+p_{1}\left(\frac{\theta_{1}^{*}}{\theta_{2}^{*}}\right) \theta_{1}>u^{\prime-1}\left(\frac{\beta}{\rho}\right)>\rho b+p_{1}\left(\frac{\theta_{1}}{\theta_{2}}\right) \theta_{1}, \\
\rho b^{*}+p_{2}\left(\frac{\theta_{1}}{\theta_{2}}\right) \theta_{2}^{*}>u^{\prime-1}\left(\frac{\beta}{\rho}\right)>\rho b^{*}+p_{2}\left(\frac{\theta_{1}^{*}}{\theta_{2}^{*}}\right) \theta_{2}^{*},
\end{gathered}
$$

as $\gamma$ increases, the home country switches from fully employment to underemployment while the foreign country switches in the reverse direction. From proposition 1, whether the foreign country is fully employed or underemployed, an increase in $\gamma$ expands (reduces) home consumption $c$ if the home country is fully employed (underemployed). Therefore, the $c$ function has a similar shape as illustrated in figure 4, in which $\bar{\gamma}=\bar{\gamma}_{F U}$ given in (35) and $\overline{\bar{\gamma}}=$ $\overline{\bar{\gamma}}_{U F}$ given in (33).

The level of $\gamma$ at which the home country turns from full employment to underemployment is either $\gamma_{c}$ in (36) or $\gamma_{c}^{\prime}$ in (37), depending on whether the foreign country is still fully employed or has already entered the area of underemployment at the turning point. From proposition 1, an increase in $\gamma$ always lowers $\omega$. As $\gamma$ increases and makes $\omega$ reach $\omega_{c}^{*}$ at which the full-employment level of $c^{*}$ in pattern (h1-f2) of (17) equals its upper bound $u^{\prime-1}(\beta / \rho)$ :

$$
\gamma_{c}^{*}=\varphi\left(\omega_{c}^{*}\right)\left(\frac{\theta_{1}}{\theta_{2}^{*}}\right) \text { where } c^{*}=\rho b^{*}+p_{2}\left(\omega_{c}^{*}\right) \theta_{2}^{*}=u^{\prime-1}\left(\frac{\beta}{\rho}\right) \text {, }
$$

the foreign country turns from underemployment to full employment. Similarly, the home country turns from full employment to underemployment when $\omega$ equals $\omega_{c}$ given in (36). 
Therefore, if $\omega_{c}$ is larger than $\omega_{c}^{*}$ given above, $\gamma$ reaches $\gamma_{c}$ before $\gamma_{c}^{*}$ and then the home country turns from full employment to underemployment while the foreign country is underemployed. If $\omega_{c}<\omega_{c}^{*}, \gamma$ reaches $\gamma_{c}^{*}$ before $\gamma_{c}$ and the foreign country turns from underemployment to full employment before the home country turns full employment to underemployment. Then, the critical value of $\gamma$ is $\gamma_{c}^{\prime}$. In either case the $c$ function has a similar shape as in figure 4.

\section{Non-negligible lending and borrowing}

The absolute value of $b$, which equals $-\gamma b^{*}$ from (16), has so far been assumed to be negligibly small so that the redistribution effect of lending and borrowing among households within a country due to a population change is ignored. This section considers the case of non-negligible $b\left(=-\gamma b^{*}\right)$ and discusses the redistribution effect.

International assets/debts are assumed to be held in real terms and evenly distributed among households within each country. Therefore,

$$
b=\frac{B}{L}, \quad b^{*}=\frac{B^{*}}{L^{*}}=-\frac{B}{L^{*}},
$$

where $B^{(*)}$ is the total net lending of the home (or foreign) country. They satisfy

$$
\begin{gathered}
\frac{d b}{d L}=-\frac{B}{L^{2}} \lesseqgtr 0 \text { and } \frac{d b^{*}}{d L^{*}}=\frac{B}{L^{* 2}} \gtreqless 0 \text { if and only if } B \gtreqless 0, \\
\frac{d b}{d L^{*}}=0, \quad \frac{d b^{*}}{d L}=0 .
\end{gathered}
$$

From the above equations, if the absolute level of $B\left(=-B^{*}\right)$ is negligibly small, as has so far been assumed, a change in $L^{(*)}$ yields no redistribution of lending and borrowing among each population. It affects $x^{(*)}$ and $c^{(*)}$ only through a change in $\omega$. Moreover, whether $b$ is negligible or not, in the case of homothetic utility the relative commodity price $\omega$ does not depend on $b$, as is clear from (17) in case F-F, (26) in case U-U, (29) in case U-F and (34) in 
case F-U. Therefore, in the case where $b$ is non-negligible, the effects of a change in $L^{(*)}$ on $x^{(*)}$ and $c^{(*)}$ consist of those through a change in $\omega$, which do not depend on $b$, and those directly through a change in $b$.

An increase in $L^{*}$ does not affect the home net lending per capita $b$ so that the previous results are valid. However, an increase in $L$ reduces (or expands) $b$ if $b$ is positive (or negative). From (17), (25) and (31), the effect on $c$ of a change in $L$ through the redistribution of $B$ is

$$
\begin{gathered}
\text { Full employment: } \frac{\partial c}{\partial L}=\frac{\partial\left[\rho b+p_{1}(\omega) \theta_{1}\right]}{\partial L}=\rho \frac{\partial b}{\partial L} \lesseqgtr 0 \quad \Leftrightarrow \quad B \gtreqless 0, \\
\text { Underemployment: } \frac{\partial c}{\partial L}=c^{\prime}(x) \frac{\partial x}{\partial b} \frac{\partial b}{\partial L}=-\frac{c^{\prime}(x) \rho}{p_{1}(\omega) \theta_{1}-c^{\prime}(x)} \frac{\partial b}{\partial L} \gtreqless 0 \quad \Leftrightarrow \quad B \gtreqless 0 .
\end{gathered}
$$

It is added to the effect through a change in $\omega$ explored in the previous sections.

Note that the direction of the additional effect depends on whether the home country is fully employed or not and whether it is a creditor or a debtor. If the home country is a creditor, for example, the additional effect of a larger home population on home consumption through redistribution of international lending is negative (or positive) in the case where the home country is fully employed (or underemployed). If the home country is a debtor, the result is just opposite.

\section{Conclusion}

Nowadays many developed countries face long-run aggregate demand deficiency although they have high potential production capacity and large wealth. This situation appears if households have insatiable preference for money (or wealth) because the relative preference for wealth accumulation over consumption does not decline as households accumulate wealth, preventing consumption from increasing. Therefore, if a country has large potential 
productivity, consumption cannot be large enough to achieve full employment, leading to secular demand stagnation.

In this case, the effect of a larger foreign population on home consumption is quite opposite to that under full employment. A larger foreign population expands supply of the foreign commodity and raises the relative price of the home commodity, which increases home real income as far as full employment prevails in the home country. Therefore, home consumption increases. If the country faces secular demand stagnation, however, a higher relative price of the home commodity due to a larger foreign population decreases demand for the home commodity, making home employment and realized income lower. This negative effect dominates the positive effect of foreign demand expansion due to a larger foreign population and hence home consumption decreases.

The same result obtains in the case of a smaller home population. A smaller home population raises the relative price of the home commodity, which improves the home terms of trade and increases home real income and consumption per capita as far as the home country attains full employment. If home productivity is so high that home households do not consume enough to achieve full employment, however, aggregate demand deficiency arises in the home country. In this case a rise in the relative price of the home commodity due to a smaller home population decreases home employment and consumption per capita.

\section{Appendix A: Stability}

The Euler equation in (8) gives

$$
\frac{\lambda^{*}}{\lambda}=\frac{u^{\prime}\left(c^{*}\right)}{u^{\prime}(c)}=\kappa=\text { constant over time, } \quad c^{*}=u^{\prime-1}\left(\kappa u^{\prime}(c)\right) .
$$

Therefore, in the case where $\left(x, x^{*}\right)=(1,1)$, from (12), (13) and lemma 1 one finds 
h12-f2: $\omega=\frac{\theta_{1}}{\theta_{2}}, \quad \frac{\delta\left(\frac{\theta_{1}}{\theta_{2}}\right)}{p_{1}\left(\frac{\theta_{1}}{\theta_{2}}\right)}\left(c+\gamma u^{\prime-1}\left(\kappa u^{\prime}(c)\right)\right)=\theta_{1} x_{1}, \quad \frac{\theta_{2}\left(1-x_{1}\right)+\theta_{2}^{*} \gamma}{\theta_{1} x_{1}}=\varphi\left(\frac{\theta_{1}}{\theta_{2}}\right)$,

h1-f2: $\frac{\theta_{2}^{*} \gamma}{\theta_{1}}=\varphi(\omega), \frac{\delta(\omega)}{p_{1}(\omega)}\left(c+\gamma u^{\prime-1}\left(\kappa u^{\prime}(c)\right)\right)=\theta_{1}$,

h1-f12: $\omega=\frac{\theta_{1}^{*}}{\theta_{2}^{*}}, \frac{\delta\left(\frac{\theta_{1}^{*}}{\theta_{2}^{*}}\right)}{p_{1}\left(\frac{\theta_{1}^{*}}{\theta_{2}^{*}}\right)}\left(c+\gamma u^{\prime-1}\left(\kappa u^{\prime}(c)\right)\right)=\theta_{1}+\theta_{1}^{*} \gamma x_{1}^{*}, \quad \frac{\theta_{2}^{*} \gamma\left(1-x_{1}^{*}\right)}{\theta_{1}+\theta_{1}^{*} \gamma x_{1}^{*}}=\varphi\left(\frac{\theta_{1}^{*}}{\theta_{2}^{*}}\right)$,

which fully determines $c$ once $\kappa$ is given. Substituting this $c$, which is constant over time, into (9) yields

$$
r=\rho . \quad \pi=\frac{v^{\prime}(m)}{u^{\prime}(c)}-\rho
$$

Applying this $\pi$ into (14) gives

$$
\dot{m}=-\left(\frac{v^{\prime}(m)}{u^{\prime}(c)}-\rho\right) m,
$$

which immediately determines $m$ (or $P$ ), and then $\pi=0$. From (15),

$$
\dot{b}=\rho b+p_{1}(\omega) \theta_{1}-c,
$$

where $\omega$ and $c$ are fully determined in (A2) once $\kappa$ is given. Because $\dot{b}$ is unstable with respect to $b, \kappa$ jumps to the level that makes $\dot{b}=0$ and the new steady state is immediately reached.

In the case where $0<x<1$ and $x^{*}=1$ equations (12) and (13) and lemma 1 yield

$$
\begin{aligned}
& \text { h12-f2: } \omega=\frac{\theta_{1}}{\theta_{2}}, \frac{\delta\left(\frac{\theta_{1}}{\theta_{2}}\right)}{p_{1}\left(\frac{\theta_{1}}{\theta_{2}}\right)}\left(c+\gamma u^{\prime-1}\left(\kappa u^{\prime}(c)\right)\right)=\theta_{1} x_{1}, \quad \frac{\theta_{2}\left(x-x_{1}\right)+\theta_{2}^{*} \gamma}{\theta_{1} x_{1}}=\varphi\left(\frac{\theta_{1}}{\theta_{2}}\right), \\
& \text { h1-f2: } \frac{\theta_{2}^{*} \gamma}{\theta_{1} x}=\varphi(\omega), \frac{\delta(\omega)}{p_{1}(\omega)}\left(c+\gamma u^{\prime-1}\left(\kappa u^{\prime}(c)\right)\right)=\theta_{1} x, \\
& \text { h1-f12: } \omega=\frac{\theta_{1}^{*}}{\theta_{2}^{*}}, \frac{\delta\left(\frac{\theta_{1}^{*}}{\theta_{2}^{*}}\right)}{p_{1}\left(\frac{\theta_{1}^{*}}{\theta_{2}^{*}}\right)}\left(c+\gamma u^{\prime-1}\left(\kappa u^{\prime}(c)\right)\right)=\theta_{1} x+\theta_{1}^{*} \gamma x_{1}^{*}, \quad \frac{\theta_{2}^{*} \gamma\left(1-x_{1}^{*}\right)}{\theta_{1} x+\theta_{1}^{*} \gamma x_{1}^{*}}=\varphi\left(\frac{\theta_{1}^{*}}{\theta_{2}^{*}}\right),
\end{aligned}
$$

which gives $x$ as a function of $c$ once $\kappa$ is given:

$$
x=x(c, \kappa) .
$$

Because unemployment appears and deflation continues in the home country, from (20) $v^{\prime}(m)=\beta$. Therefore, from (9) and (23), one obtains an autonomous dynamic equation of $c$ : 


$$
\eta \frac{\dot{c}}{c}=\Phi(c) \equiv \frac{\beta}{u^{\prime}(c)}-\rho-\alpha(x(c, \kappa)-1) .
$$

Because in the present case the first inequality in (21) holds and hence

$$
\Phi\left(c^{f}\right) \equiv \frac{\beta}{u^{\prime}\left(c^{f}\right)}-\rho>0
$$

in order for the steady-state $c$ to exist it must be valid that

$$
\Phi(0)<0
$$

and then

$$
\Phi^{\prime}(c)>0
$$

around the steady state, where $0<c<c^{f}$. Thus, the dynamics of $c$ given by (A3) is unstable and $c$ instantaneously jumps to the level that makes (A3) equal zero. This $c$ is a function of $\kappa$ and hence $x(c, \kappa)$ is also determined for a given $\kappa$. In patterns h12-f2 and h1-f12 $\omega$ is constant and in pattern h1-f3 $\omega$ is a function of $x$. By substituting those values to (30) gives the dynamics of $b$, one finds it to be unstable with respect to $b$. Therefore, $\kappa$ is determined so that $\dot{b}=0$ and then all variables jump to respective steady-state levels and stay there. The case where $x=1$ and $0<x^{*}<1$ is analogously treated.

Finally, in the case where both inequalities in (21) are valid and hence $0<x<1$ and $0<$ $x^{*}<1$, from (12), (26) and (A1) one finds

$$
\begin{aligned}
& \text { h12-f2: } \frac{\delta\left(\frac{\theta_{1}}{\theta_{2}}\right)}{p_{1}\left(\frac{\theta_{1}}{\theta_{2}}\right)}\left(c+\gamma u^{\prime-1}\left(\kappa u^{\prime}(c)\right)\right)=\theta_{1} x_{1}, \quad \frac{\theta_{2}\left(x-x_{1}\right)+\theta_{2}^{*} \gamma x^{*}}{\theta_{1} x_{1}}=\varphi\left(\frac{\theta_{1}}{\theta_{2}}\right) ; \\
& \text { h1-f2: } \frac{\delta(\omega)}{p_{1}(\omega)}\left(c+\gamma u^{\prime-1}\left(\kappa u^{\prime}(c)\right)\right)=\theta_{1} x, \quad \frac{\theta_{2}^{*} \gamma x^{*}}{\theta_{1} x}=\varphi(\omega) ; \\
& \text { h1-f12: } \frac{\delta\left(\frac{\theta_{1}^{*}}{\theta_{2}^{*}}\right)}{p_{1}\left(\frac{\theta_{1}^{*}}{\theta_{2}^{*}}\right)}\left(c+\gamma u^{\prime-1}\left(\kappa u^{\prime}(c)\right)\right)=\theta_{1} x+\theta_{1}^{*} \gamma x_{1}^{*}, \quad \frac{\theta_{2}^{*} \gamma\left(x^{*}-x_{1}^{*}\right)}{\theta_{1} x+\theta_{1}^{*} \gamma x_{1}^{*}}=\varphi\left(\frac{\theta_{1}^{*}}{\theta_{2}^{*}}\right) .
\end{aligned}
$$

From (9) and (23),

$$
\left(\eta \frac{\dot{c}}{c}-\rho=\right) \frac{\beta}{u^{\prime}(c)}-\alpha(x-1)=\frac{\beta}{\kappa u^{\prime}(c)}-\alpha\left(x^{*}-1\right)\left(=\eta^{*} \frac{\dot{c}^{*}}{c^{*}}-\rho\right),
$$

and hence together with (A4) one obtains 


$$
x=x(c, \kappa) .
$$

Therefore, the same logic as that for the stability of the dynamics of $b$ in the asymmetric case mentioned above applies to the present case. The steady state is immediately reached.

In sum, in all cases the steady state is instantaneously reached and the economy stays there -i.e., lemma 2 holds.

\section{Appendix B: Wealth preference}

The household behavior with wealth preference is to maximize

$$
\int_{0}^{\infty}[u(c)+v(m)+\phi(a)] \exp (-\rho t) d t
$$

where $v(m)$ now represents the transaction motive and $\phi(a)$ is wealth preference, subject to the flow budget equation and asset constraint:

$$
\dot{a}=r a+w x-c-R m, a=m+b .
$$

Given the Hamiltonian function of the utility maximization:

$$
H=u(c)+v(m)+\phi(a)+\lambda(r a+w x-c-R m)
$$

the first-order optimal conditions are

$$
\lambda=u^{\prime}(c), \quad \lambda R=v^{\prime}(m), \quad \frac{\dot{\lambda}}{\lambda}=\rho-r-\phi^{\prime}(a)
$$

They yield

$$
\eta \frac{\dot{c}}{c}=\frac{v^{\prime}(m)+\phi^{\prime}(a)}{u^{\prime}(c)}-\rho-\pi, \quad R=\frac{v^{\prime}(m)}{u^{\prime}(c)}
$$

instead of (9). Replacing the property of (20) by

$$
v^{\prime}(\infty)=0, \quad \phi^{\prime}(\infty)=\beta>0,
$$

and applying them to the above equations yields

$$
\frac{\beta}{u^{\prime}(c)}=\rho+\pi \text { and } R=0 \text { for } m \rightarrow \infty \text {. }
$$


The first equation is the same as (24) and the second equation implies a zero nominal interest rate under stagnation with persistent deflation.

\section{Appendix C: Derivation of the properties in (27) and (31)}

Because the inequalities in (21) are valid in case U-U, using (24) one obtains

$$
c(1)=u^{\prime-1}(\beta / \rho)<\rho b+p_{1}(\omega) \theta_{1}, \quad c(1)=u^{\prime-1}(\beta / \rho)<\rho b^{*}+p_{2}(\omega) \theta_{2}^{*},
$$

implying that the left-hand side of each equation in (25) is smaller than the right-hand side when $x=1$ (or $x^{*}=1$ ). Therefore, in order for the solution of $x$ (or $x^{*}$ ) in (25) to exist in the range of $(0,1)$, the left-hand side of (25) must be larger than the right-hand side when $x=0$ (or $\left.x^{*}=0\right)$-i.e.,

$$
c(0)>\rho b^{(*)} \text {. }
$$

Then, in the neighborhood of the solution of $x\left(\right.$ or $\left.x^{*}\right)$,

$$
c^{\prime}(x)<p_{1}(\omega) \theta_{1}, \quad c^{\prime}\left(x^{*}\right)<p_{2}(\omega) \theta_{2}^{*}
$$

The first property is the same as (31).

Totally differentiating the two equations in pattern (h1-f2) of (26) and applying $\varphi^{\prime}<0$ in (12) and the properties in (A5) to the results yields

$$
\begin{gathered}
\Omega \frac{d x}{x}=\left[p_{2}(\omega) \theta_{2}^{*}-c^{\prime}\left(x^{*}\right)\right] \gamma x^{*}\left(\frac{d \gamma}{\gamma}-\frac{\varphi \prime}{\varphi} d \omega\right), \\
\Omega \frac{d x^{*}}{x^{*}}=-\left[p_{1}(\omega) \theta_{1}-c^{\prime}(x)\right] x\left(\frac{d \gamma}{\gamma}-\frac{\varphi^{\prime}}{\varphi} d \omega\right), \\
\Omega=\left[p_{1}(\omega) \theta_{1}-c^{\prime}(x)\right] x+\left[p_{2}(\omega) \theta_{2}^{*}-c^{\prime}\left(x^{*}\right)\right] \gamma x^{*}>0 .
\end{gathered}
$$

Because $\varphi^{\prime}<0$ in (12), these equations and (A5) give

$$
\hat{x}_{\omega}(\omega, \gamma)>0, \quad \hat{x}_{\gamma}(\omega, \gamma)>0 ; \quad \hat{x}_{\omega}^{*}(\omega, \gamma)<0, \quad \hat{x}_{\gamma}^{*}(\omega, \gamma)<0
$$

where $\hat{x}^{(*)}(\omega, \gamma)$ is shown in (26). From lemma 2 and the home current-account equation in (15) into which $\hat{x}(\omega, \gamma)$ is substituted, one finds 


$$
\dot{b}=\rho b+p_{1}(\omega) \theta_{1} \hat{x}(\omega, \gamma)-c(\hat{x}(\omega, \gamma))=0
$$

which gives (25). By assuming that $\dot{b}$ satisfies the Marshall-Lerner condition, from (5), (A5) and (A6) one obtains

$$
\begin{gathered}
\dot{b}_{\omega}\left(\equiv \frac{\partial \dot{b}}{\partial \omega}\right)=-\gamma \dot{b}_{\omega}^{*}=p_{1}^{\prime}(\omega) \theta_{1} x+\left[p_{1}(\omega) \theta_{1}-c^{\prime}(x)\right] \hat{x}_{\omega}>0 \\
\dot{b}_{\gamma}\left(\equiv \frac{\partial \dot{b}}{\partial \gamma}\right)=\left[p_{1}(\omega) \theta_{1}-c^{\prime}(x)\right] \hat{x}_{\gamma}>0 \\
\frac{d \omega}{d \gamma}=-\frac{\dot{b}_{\gamma}}{\dot{b}_{\omega}}<0 .
\end{gathered}
$$

From (5), (A5), (A6) and (A7),

$$
\begin{gathered}
\frac{d x}{d \gamma}=\hat{x}_{\gamma}+\hat{x}_{\omega} \frac{d \omega}{d \gamma}=\frac{p_{1}^{\prime}(\omega) \theta_{1} x \hat{x}_{\gamma}}{\dot{b}_{\omega}}<0, \quad \frac{d c}{d \gamma}=c^{\prime}(x) \frac{d x}{d \gamma}<0 \\
\frac{d x^{*}}{d \gamma}=\hat{x}_{\gamma}^{*}+\hat{x}_{\omega}^{*} \frac{d \omega}{d \gamma}=\frac{p_{2}^{\prime}(\omega) \theta_{2}^{*} x^{*} \hat{x}_{\gamma}^{*}}{\dot{b}_{\omega}^{*}}>0, \quad \frac{d c^{*}}{d \gamma}=c^{\prime}\left(x^{*}\right) \frac{d x^{*}}{d \gamma}>0, \quad \frac{d\left(\frac{\gamma x^{*}}{x}\right)}{d \gamma}>0 .
\end{gathered}
$$

These imply the properties in (27).

\section{REFERENCES}

Adolfson M., S. Laséen, J. Lindé and M. Villani (2007) “Bayesian Estimation of an Open Economy DSGE Model with Incomplete Pass-through”, Journal of International Economics, Vol. 72, pp. 481-511.

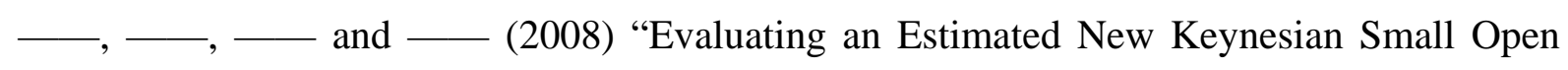
Economy Model”, Journal of Economic Dynamics and Control, Vol. 32, pp. 2690-2721. Aghion, P., A. Banerjee and T. Piketty (1999) “Dualism and Macroeconomic Volatility”, Quarterly Journal of Economics, Vol. 114, pp. 1359-1397.

Akerlof, G. A. (1982) “Labor Contracts as Partial Gift Exchange”, Quarterly Journal of Economics, Vol. 97, pp. 543-569.

— and J. L. Yellen (1990) “The Fair-Wage Effort Hypothesis and Unemployment”, Quarterly Journal of Economics, Vol. 105, pp. 255-284. 
Azariadis, C. and L. Kaas (2016) “Capital Misallocation and Aggregate Factor Productivity”, Macroeconomic Dynamics, Vol. 20, pp. 525-543.

Calvo, G. (1983) “Staggered Prices in a Utility Maximizing Framework”, Journal of Monetary Economics, Vol. 12, pp. 383-398.

Christiano, L. J., M. Eichenbaum and C. L. Evance (2005) "Nominal Rigidities and the Dynamic Effects of a Shock to Monetary Policy”, Journal of Political Economy, Vol. 113, pp. 1-45.

Erceg, C. J., W. H. Dale and A. T. Levin (2000) “Optimal Monetary Policy with Staggered Wage and Price Contracts”, Journal of Monetary Economics, Vol. 46, pp. 281-313.

Eggertsson, G. B. and P. Krugman (2012) “Debt, Deleveraging, and the Liquidity Trap: A Fisher-Minsky-Koo Approach”, Quarterly Journal of Economics, Vol. 127, pp. 1469 $-1513$.

Hall, R. (2011) “The Long Slump”, American Economic Review, Vol. 101, pp. 431-469.

Hayashi, F. and E. C. Prescott (2002) “The 1990s in Japan: A Lost Decade”, Review of Economic Dynamics, Vol. 5, pp. 206-235.

Kehoe T. J. and E. C. Prescott (2002) “Great Depressions of the 20th Century”, Review of Economic Dynamics, Vol. 5, pp. 1-18.

Kiyotaki, N. and J. Moore (1997) “Credit Cycle”, Journal of Political Economy, Vol. 105, pp. 211-248.

Krugman, P. R. (1998) “It’s Baaack: Japan’s Slump and the Return of the Liquidity Trap”, Brookings Papers on Economic Activity, Vol. 2, pp. 137-187.

Liu, Z. and P. Wang (2014) “Credit Constraints and Self-fulfilling Business Cycles”, American Economic Journal: Macroeconomics, Vol. 6, pp. 32-69.

Matsuyama, K. (2007) “Credit Traps and Credit Cycles”, American Economic Review, Vol. 97, pp. 503-516. 
McGratten, E. R. and E. C. Prescott (2012) "The Great Recession and Delayed Economic Recovery”, in L. E. Ohanian, J. B. Taylor and I. J. Wright, eds., Government Policies and the DELAYED Economic Recovery, Hoover Institution Press: Stanford University, pp. 115-154.

Michaillat, P. and E. Saez (2014) “An Economic Business-Cycle Model”, NBER Working Paper 19777.

Michau, J.-B. (2015) “Secular Stagnation: Theory and Remedies”, hal-01211667, Centre National de la Recherche Scientifique, Ecole Polytechnique.

Ono, Y. (1994) Money, Interest, and Stagnation, Clarendon Press: Oxford.

_ (2001) “A Reinterpretation of Chapter 17 of Keynes’s General Theory: Effective Demand Shortage under Dynamic Optimization”, International Economic Review, Vol. 42, pp. 207-236.

_ (2006) "International Asymmetry in Business Activity and Appreciation of a Stagnant Country's Currency”, Japanese Economic Review, Vol. 57, pp. 101-120.

—_ (2014) "International Economic Interdependence and Exchange-rate Adjustment under Persistent Stagnation”, Japanese Economic Review, Vol. 65, pp. 70-92.

_ (2017) “Macroeconomic Interdependence between a Stagnant and a Fully Employed Country”, Japanese Economic Review, forthcoming, DOI: 10.1111/jere.12156.

— and J. Ishida (2014) “On Persistent Demand Shortages: A Behavioral Approach”, Japanese Economic Review, Vol. 65, pp. 42-69.

— with Dynamic Optimizing Agents”, Japanese Economic Review, Vol. 55, pp. 355-371.

Ono, Y. and A. Shibata (2006) “Long-run Specialization”, Review of International Economics, Vol. 14, pp. 1-15.

Pissarides, C. A. (2000) Equilibrum Unemployment Theory, $2^{\text {nd }}$ edition, Cambridge (MA): 
MIT Press.

Schmitt-Grohé, S. and M. Uribe (2016) “Downward Nominal Wage Rigidity, Currency Pegs, and Involuntary Unemployment”, Journal of Political Economy, Vol. 124, No. 5, pp. 1466-1514.

— and — (2017) “Liquidity Traps and Jobless Recoveries”, American Economic Journal: Macroeconomics, Vol. 9, No. 1, pp. 165-204.

Smets, F. and R. Wouters (2003) “An Estimated Stochastic Dynamic General Equilibrium Model of the Euro Area”, Journal of the European Economic Association, Vol. 1, pp. 1123-1175.

— and — (2005) "Bayesian New Neoclassical Synthesis (NNS) Models: Modern Tools for Central Banks”, Journal of the European Economic Association, Vol. 3, pp. 422-433. — and — (2007) "Shocks and Frictions in US Business Cycles: A Bayesian DSGE Approach”, American Economic Review, Vol. 97, pp. 586-606.

Yun, T. (1996) “Nominal Price Rigidity, Monetary Supply Endogeneity, and Business Cycles”, Journal of Monetary Economics, Vol. 37, pp. 345-370. 